
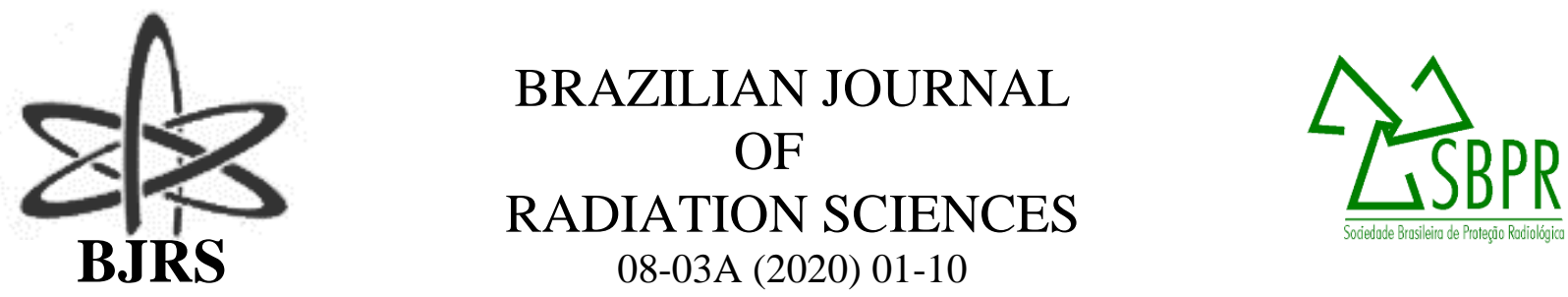

\title{
Preliminary neutronic study of the S-PRISM fast reactor
}

\author{
João Manoel Losada Moreira \\ Programa de Pós-graduação em Energia \\ Universidade Federal do ABC \\ joaoufabc@gmail.com
}

\begin{abstract}
Waste management is a challenge currently faced by nuclear energy worldwide. Most nuclear power plants operate in a once-through cycle and all spent nuclear fuel is stored in long term. Fast reactors can recycle $96 \%$ of the material in spent nuclear fuel of thermal reactors, reducing drastically the time required to store the waste. The S-PRISM reactor is a modular, pool-type sodium-cooled fast reactor that can operate with a variety of fuel types. In this study, the advantages presented by fast reactors were briefly discussed and a preliminary analysis of the fuel pin cells was made. It was found that the isothermal coefficient of reactivity was lower than a regular PWR's, with neutron leakage playing a major role instead of coolant or doppler expansion. The $\mathbf{k}_{\infty}$ showed decrease for the driver pin and increase for the blanket pin during burnup; opposite behavior was observed for the conversion ratio. No results for pin analysis were found in literature for comparison. As the simulations were carried out separately instead of in a system, the results are not representative of the whole core behavior, but must be seen as a path to understand the different types of pin influence in the system.
\end{abstract}




\section{INTRODUCTION}

One of the challenges the nuclear energy industry currently faces is the waste management issue. However clean and safe nuclear energy has proven to be, the waste accumulation compromises the sustainability factor. The International Atomic Energy Agency [1] states that "radioactive waste is to be managed in a manner that protects human health and the environment, now and in the future, without imposing undue burdens on future generations".

Spent nuclear fuel from thermal reactors is composed of $95 \%$ uranium, $1 \%$ transuranics and 4 $\%$ fission products, approximately. In a once-through cycle all these materials are required to go to geological disposal facilities, i. e., uranium, transuranics and fission products. Transuranics include $\mathrm{Pu}$ isotopes and the minor actinides, $\mathrm{Am}, \mathrm{Np}$ and $\mathrm{Cm}$ isotopes [2].

Minor actinides are the most concerning elements, once they present high radiotoxicity and a long half-life, requiring storage for about 100,000 years. The long storage time is a great imposition for next generations, unlike expected from radioactive waste management. An effective option to reduce the radiotoxicity levels related to these elements while attaining a closed fuel cycle is to promote their transmutation through fission in a fast nuclear reactor - the capture-to-fission ratio of the minor actinides is much lower in the fast spectrum than in the thermal spectrum, indicating that these elements will most likely suffer fission upon neutron interaction, showing a fuel-like behavior.

Fast reactors, in principle, can recycle $96 \%$ of the material in spent nuclear fuel of thermal reactors (uranium and transuranics), reducing drastically the time required to store the radioactive waste generated in the use of nuclear power [2,3].

The first nuclear reactor to successfully generate electricity was the Experimental Breeder Reactor - I (EBR-I), a fast reactor with a liquid sodium-potassium coolant. EBR-II, with a liquid sodium coolant, operated for over 30 years generating $20 \mathrm{MW}$ of electricity. Another sodium cooled fast reactor built by General Electric supplied power for the second American submarine built (USS Seawolf). Later in the 1990's, GE led a group of engineers to propose the modular fast reactor named PRISM (Power Reactor Innovative Small Module) under the US Advanced Liquid Metal Reactor program. The Generation IV International Forum selected six reactor designs that met a set 
of criteria based on safety, reliability, sustainability, and minimization of high-level waste, being three of them based on fast reactor technology. The coolant of these fast reactor designs were liquid sodium, liquid lead and helium gas [2].

The purpose of this study is twofold: first, to discuss the advantages presented by fast reactors to reduce long-lived waste (transuranics) and avoid thousands of years in storage requirement; and second, to perform a preliminary analysis of the fuel pin cell in the S-PRISM sodium cooled fast reactor [4].

\section{MOTIVATION TO CONSIDER FAST REACTORS}

Fast reactors have a harder spectrum when compared to thermal reactors, and thus important processes that occur in the latter are of minor importance or avoided, namely fission by thermal neutrons and neutron moderation.

Since U-238 and all transuranic isotopes can undergo fission upon interaction with fast neutrons, all these isotopes are thus fuel materials and can be transmuted to fission products. In principle, fast reactors can consume all long-lived transuranic isotopes, eliminate the long-lived transuranic high-level waste and reduce the storage problem to, essentially, fission products.

Fast reactors can be designed to have high conversion ratios and, if they are greater than unity, fast reactors can be breeders. But they can also be designed to have low conversion factors and instead be put to work as a transuranic burner. Thus, fast reactors can be utilized to burn (or incinerate) long-lived actinides and reduce the inventory of these high-level radioactive waste materials.

Figure 1 shows the expected growth back in 1992 of the $\mathrm{Pu}$ inventories in the world. The behavior of the inventory of other transuranic isotopes would be similar and tend to stabilize due to their fission caused by fast neutrons in fast reactors. The once-through fuel cycle tends to increase the inventory, since all spent nuclear fuel is shipped to a high-level waste storage facility. Thermal recycling through Purex reprocessing would decrease the $\mathrm{Pu}$ inventory but it would still grow continuously due to the limitations faced by thermal reactors when it comes to recycling. 
Figure 1: Effect of recycling in worldwide inventory of Pu. The inventory of other transuranic isotopes would show similar behavior of stabilization [3].

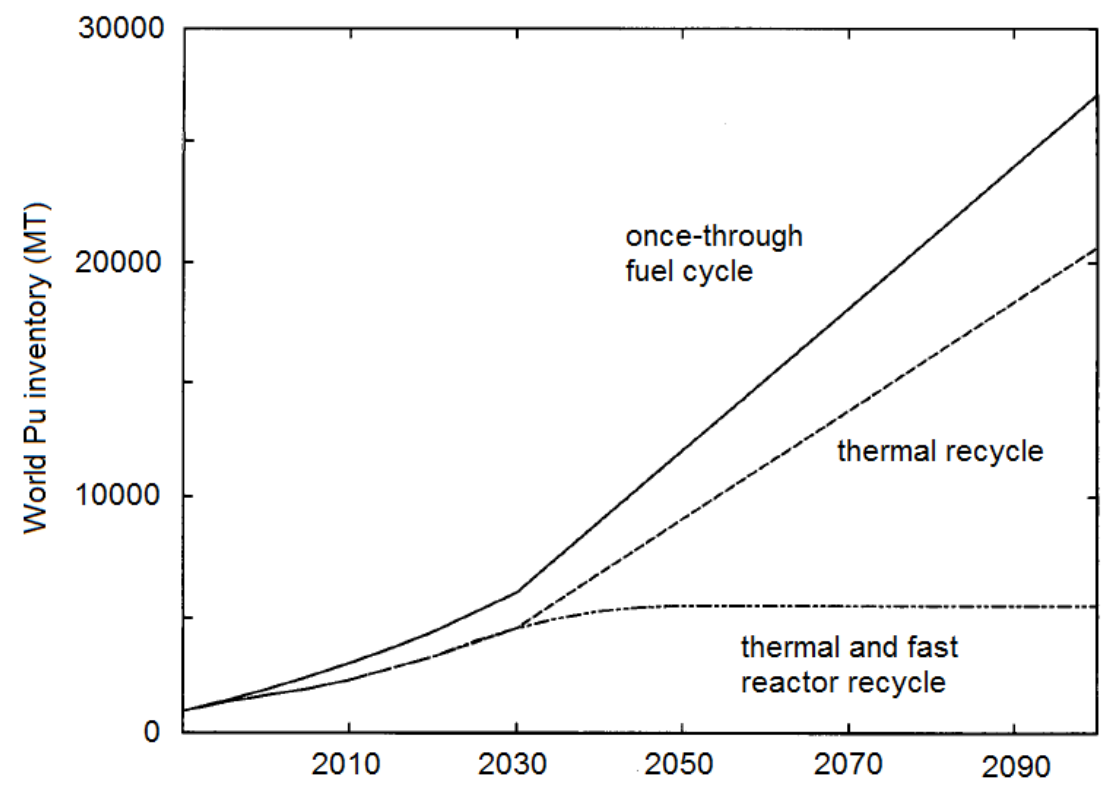

Thermal recycling coupled with fast reactor recycling, on the other hand, levels off the $\mathrm{Pu}$ inventory as shown in Figure 1. More interestingly, this inventory would be located almost entirely inside the power reactors generating electricity. Designed with an adequate conversion ratio, a fast reactor can burn the $\mathrm{Pu}$ and minor actinide inventories so that they do not increase and stay constant over time. The transuranic inventory consigned as waste can be maintained essentially zero.

\section{METHODS AND DATA}

\subsection{Attributes of the S-PRISM fast reactor}

The S-PRISM was chosen as the baseline model for several of its characteristics. It is a modular, pool-type sodium-cooled fast reactor that can operate with oxide, metal or nitride fuel. The possibility of using metal fuel allows for an easier manufacturing and inclusion of actinides. Also, the metal fuel does not interact chemically with sodium, while displaying high heat transport, with a thermal conductivity approximately seven times greater than oxide fuel, allowing for more efficient heat removal. Although oxide fuel has a higher melting temperature, both fuel types operate at 
similar margins to melt because the metal fuel operates at a lower centerline temperature due to its high thermal conductivity [2]. This work focus on the metal fuel performance. The metal core design is shown on Fig. 2.

Figure 2: S-PRISM metal fuel core design [4].

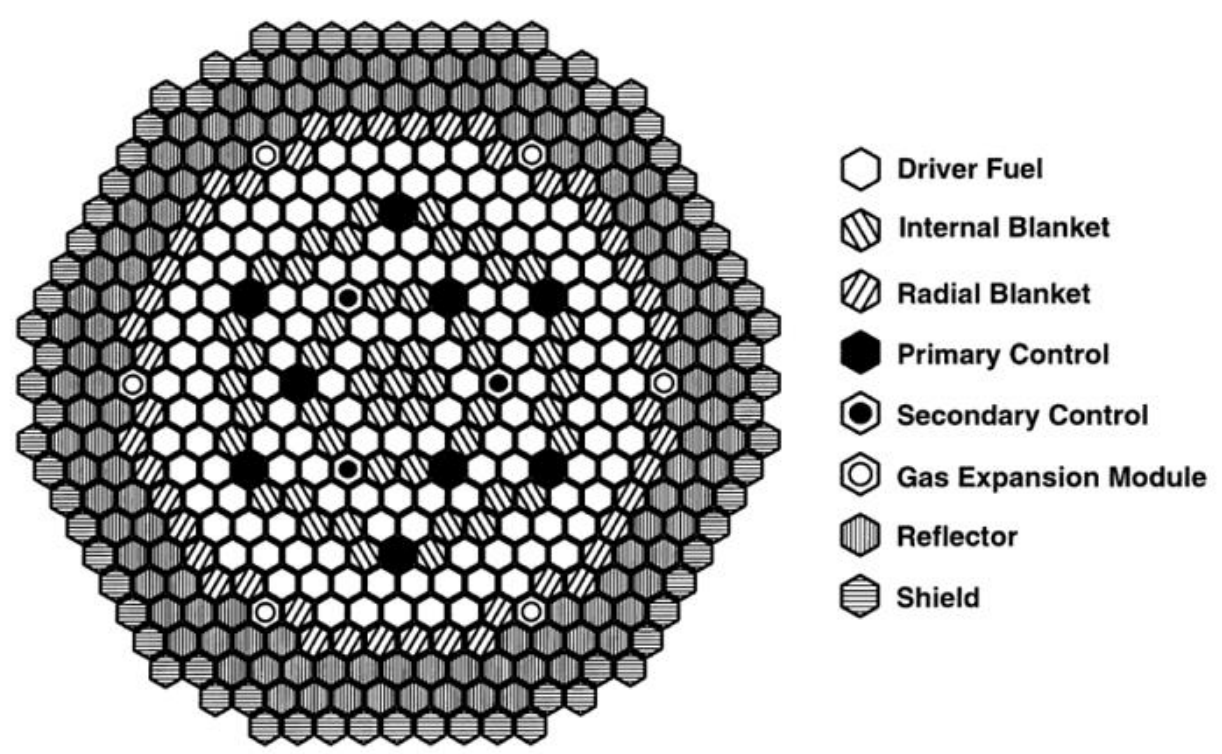

Assemblies for driver and blanket have the same hexagonal pitch, but the driver assemblies have 271 fuel pins while blanket assemblies have 127 fuel pins. The driver pitch is $1.01 \mathrm{~cm}$ and blanket pitch is $1.33 \mathrm{~cm}$ (both hexagonal), with a fuel radius of $0.27 \mathrm{~cm}$ for the driver and $0.5 \mathrm{~cm}$ for the blanket. Both fuel types have gap thickness of $0.04 \mathrm{~cm}$ and clad thickness of $0.06 \mathrm{~cm}$.

The internal and radial blankets have the same fuel composition at BOL. The smeared density of the fuel is $75 \%$ of the theoretical density, allowing for more expansion and consequently increasing burnup. Table 1 shows the metal fuel composition. Other parameters can be found in the literature $[2,4,6]$.

\subsection{Modeling and simulation}

The different fuel pins - driver and blanket - were modeled on MCNP6 [7], reflected on the sides and with vacuum on the top and bottom. The Monte Carlo-based package was used for a 
preliminary analysis of the fuel pins, including temperature coefficients of reactivity and variation of pin size (only for the driver pin). Library ENDF/B-VIII [8] was processed on NJOY [9] to obtain the correct data in the temperatures needed for the analysis. Also, a 600 days burnup (first fuel cycle) was promoted to verify the pins' reactivity and conversion ratio behavior during the cycle. Fig. 3 shows the detail of the driver fuel pin modeled in MCNP, containing a long fission gas plenum on top of the fuel, also serving as an upper axial shield (present both in driver and blanket pins).

Table 1: S-PRISM metal fuel composition by weight [6].

\begin{tabular}{lcc}
\hline \multicolumn{1}{c}{ Material } & Driver & Blanket \\
\hline Natural uranium & $69.5 \%$ & $85.1 \%$ \\
\hline Fissile plutonium & $13.7 \%$ & $3.3 \%$ \\
\hline Non-fissile plutonium & $3.4 \%$ & $0.8 \%$ \\
\hline Minor actinides & $3.4 \%$ & $0.8 \%$ \\
\hline $\mathrm{Zr}$ & $10.0 \%$ & $10.0 \%$ \\
\hline
\end{tabular}

Figure 3: Driver fuel pin as modeled in MCNP.

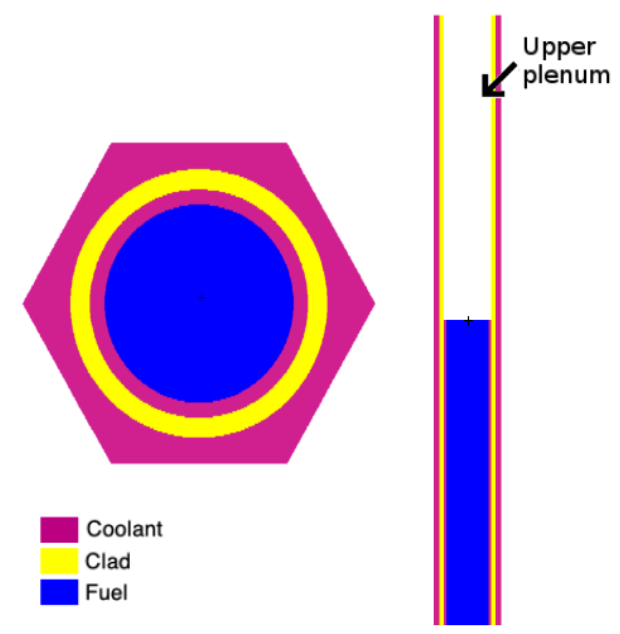

Initially setting the number of cycles to 400 in MCNP, the error values were considered too high for the small differences encountered in reactivity between temperatures. The number of cycles was 
then increased to 4000 , which required much more computational time than before, limiting the number of scenarios simulated.

\section{RESULTS AND DISCUSSION}

Table 2 shows the isothermal coefficients of reactivity for temperatures of $100{ }^{\circ} \mathrm{C}$ and $500{ }^{\circ} \mathrm{C}$ for the driver fuel pin. Table 3 shows values of $\alpha_{i s o}$ as a function of active core height, also for the driver pin.

Table 3: $\alpha_{\text {iso }}$ as a function of active core height at $525^{\circ} \mathrm{C}$.

\begin{tabular}{cc}
\hline Core height $(\mathrm{cm})$ & $\alpha_{\text {iso }}$ \\
\hline 101.6 & $+0.4574 \pm 0.0003$ \\
\hline 50 & $-0.7682 \pm 0.0004$ \\
\hline
\end{tabular}

The values of $\alpha_{\text {iso }}$ are extremely low when compared to a PWR's. However, as can be seen on Table 3 , it is possible to reach an adequate value of $\alpha_{\text {iso, }}$, in this case, by diminishing the active pin height. We can infer by that that neutron leakage has a higher influence on reactivity than coolant or fuel expansion.

Figure 4 shows $\mathrm{k}_{\infty}$ values for driver and blanket fuel pins as a function of burnup. It is noticeable that at the same time $\mathrm{k}_{\infty}$ values for driver fuel show a high value at BOL decreasing with time $\left(-13,000 \mathrm{pcm}\right.$, approximately), blanket fuel $\mathrm{k}_{\infty}$ values increase with time (increasing in almost $6,000 \mathrm{pcm})$.

The conversion Ratio shows the opposite behavior, as can be seen in Figure 5: high values for blanket at BOC decreasing with time and low values for driver at BOC increasing slowly. 
Figure 4: $k_{\infty}$ versus burnup expressed in equivalent full power days for the driver and blanket regions.

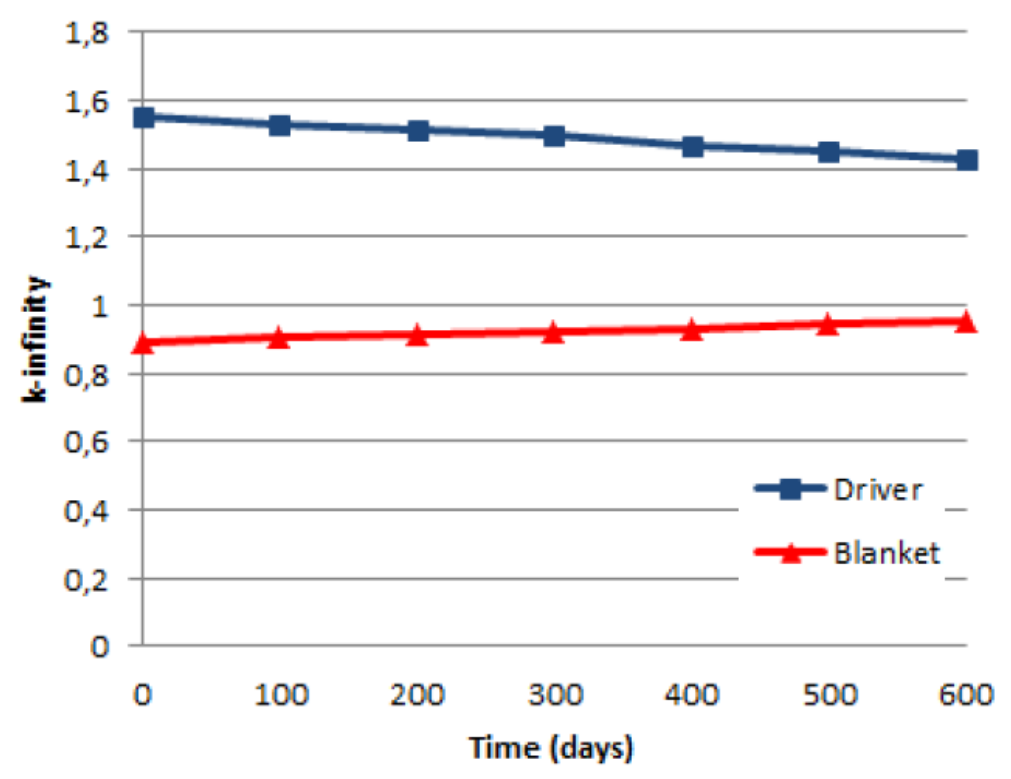

Figure 5: Conversion ratio versus burnup expressed in equivalent full power days for the driver and blanket regions.

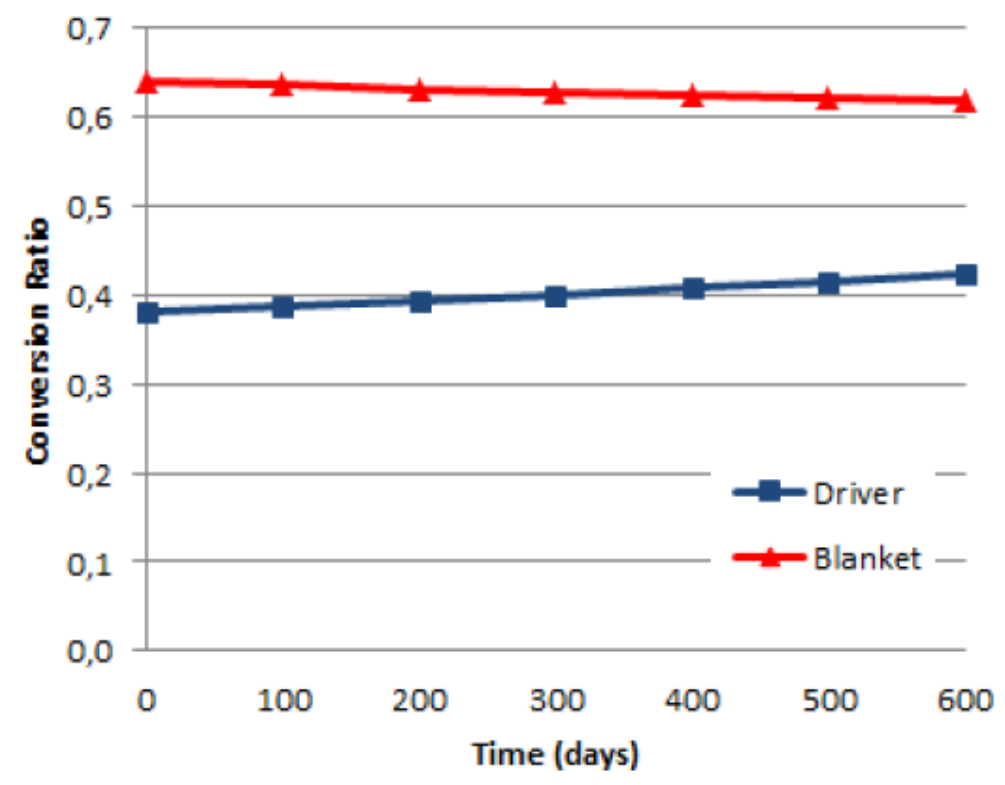




\section{CONCLUSION}

A good alternative to spent nuclear fuel storage is to promote its burn in a fast reactor. Studies have shown the viability of the S-PRISM for that end. While there is data in literature showing analysis of the whole S-PRISM core for several different configurations, no data was found on the fuel pin analysis for comparison. This led to a difficulty in the result analysis of this work. It was found that, for the standard driver fuel pin, the values are very low when compared to those of a PWR. However, an efficient reactivity decrease could be reached by varying the pin height, which shows that neutron leakage has an important role on reactivity in this case.

Another important result found was on the burnup simulation of both types of fuel pin, which showed that $\mathrm{k}_{\infty}$ decreases with burnup, as expected, for the driver fuel pin, but it increases for the blanket pin. The opposite behavior happens when conversion ratio is analyzed. These results indicate that the relation between the pins' behavior and the whole system might be more complicated than initially imagined.

It is necessary to remember that the simulations were carried out separately, and not as a system, meaning that these results, as important as they can be, do not reflect the behavior of the core. Instead, they show the path to better understand the role of each fuel type and geometry distribution throughout the core. Further analysis of the pins and simulation of the full core will clarify the found results. 


\section{ACKNOWLEDGMENT}

The authors want to thank the support provided by Coordenação de Aperfeiçamento de Pessoal de Nível Superior (CAPES) for the Programa de Pós-graduação em Energia of Universidade Federal do ABC.

\section{REFERENCES}

[1] IAEA. Management of Waste from the Use of Radioactive Material in Medicine, Industry, Agriculture, Research and Education. Safety Guide WSG2, International Atomic Energy Agency (2005).

[2] Triplett B. S., Loewen E. P., Dooies B. J. Dooies. PRISM: a competitive small modular sodiumcooled reactor, Nuclear Technology, 178, pp. 186-200 (2012).

[3] Hannum W. H., Wade D. C., McFarlane H. F., Hill, R. N. Non-proliferation and safeguards aspects of the IFR, Progress in Nuclear Energy, 31, pp. 203-217, (1997).

[4] Dubberley A., Wu T., Kubo S. S-PRISM high burnup metal-fuel core design for session 3: Future deployment programs and issues. Proceeding of International Congress on Advances in Nuclear Power Plants - ICAPP, Cordoba, Spain, May 4-7 (2003).

[5] Lamarsh J. R., Baratta A. J., Introduction to Nuclear Engineering, Prentice Hall (2001).

[6] Sumner T., Ghiaasiaan S.M. Effects of fuel type on the safety characteristics of a sodium-cooled fast reactor: Part I: Background, modeling tools and pre-transient calculations, Annals of Nuclear Energy, 38, pp. 1559-1568, (2011).

[7] LANL. A General Monte Calo N-Particle (MCNP) Transport Code, http://www.mcnp.lanl.gov (2019).

[8] Brown D. A., Chadwick M. B., Capote R. et al. ENDF/B-VIII. 0: the 8th major release of the nuclear reaction data library with CIELO-project cross sections, new standards and thermal scattering data", Nuclear Data Sheets, 148, pp.1-142 (2018).

[9] R. Macfarlane, D. W. Muir, R. M. Boicurt, A. C. Kahler III and J. L. Conlin, IThe NJOY Nuclear Data Processing System, Version 2016 (No. LA-UR-17-20093)". Los Alamos National Lab. (LANL), Los Alamos, NM (United States). 